\title{
Post-treatment with propofol inhibits inflammatory response in LPS-induced alveolar type II epithelial cells
}

\author{
XILUN YANG and LING MA
}

\begin{abstract}
Department of Anesthesiology, Shengjing Hospital of China Medical University, Shenyang, Liaoning 110004, P.R. China
\end{abstract}
Received November 3, 2021; Accepted January 12, 2022

DOI: $10.3892 /$ etm.2022.11174

\begin{abstract}
Over-inflammation and severe lung injury are major causes of morbidity and mortality in patients with coronavirus disease 2019 (COVID-19). With the COVID-19 pandemic, an increasing number of patients with preexisting lung injury and inflammation are undergoing surgery or artificial ventilation under sedation in intensive care units, where 2,6-diisopropylphenol (propofol) is a commonly used drug for sedation. The aim of the present study was to investigate whether post-inflammation treatment with propofol protects epithelial type II cells against inflammation in an in vitro model of inflammation. The A549 cell line, characterised as epithelial type II cells, were exposed to lipopolysaccharide (LPS) for $2 \mathrm{~h}$ and subsequently treated with different concentrations of propofol $(0,10,25$ or $50 \mu \mathrm{M}$ ) for $3 \mathrm{~h}$. Western blot and reverse transcription-quantitative PCR analyses were used to detect the protein and mRNA expression levels, respectively, of CD14 and Toll-like receptor 4 (TLR4). Immunofluorescence staining was used to detect the in situ CD14 and TLR4 expression in epithelial type II cells. Tumor necrosis factor (TNF)- $\alpha$ production was also examined using ELISA. LPS significantly increased the expression of CD14 and TLR4, as well as the secretion of TNF- $\alpha$. Post-treatment with 25 and $50 \mu \mathrm{M}$ propofol of the LPS-treated cells significantly decreased CD14 and TLR4 expression, as well as TNF- $\alpha$ secretion, compared with the cells treated with LPS only, indicating that post-treatment with propofol alleviated inflammation and this effect was dose-dependent. The present study suggested that treatment with propofol after LPS administration has a protective effect on epithelial type II cells.
\end{abstract}

\section{Introduction}

The severe acute respiratory syndrome coronavirus 2 (SARS-CoV-2) virus has infected hundreds of millions of

Correspondence to: Dr Ling Ma, Department of Anesthesiology, Shengjing Hospital of China Medical University, 36 Sanhao Street, Shenyang, Liaoning 110004, P.R. China

E-mail: maling27@hotmail.com

Key words: propofol, lipopolysaccharides, Toll-like receptor 4, CD14, epithelial type II cell individuals, according to the World Health Organization coronavirus disease 2019 (COVID-19) Dashboard, and raised worldwide caution. It is able to lead to serious lung inflammation, pneumonia, acute lung injury (ALI) and even acute respiratory distress syndrome (ARDS) in vulnerable individuals (1). One of the most common target organs attacked by bacteria and viruses is the lung (2-4), and lung injury is frequently associated with inflammation. Lipopolysaccharide (LPS), a vital component of the outer cell wall of gram-negative bacteria, is thought to be one of the major causes of inflammation $(5,6)$. LPS is also considered the main toxic substance damaging the lung. It usually enters the organs as part of the bacterial outer membrane, contributing to local inflammation and systemic toxicity (7). LPS is closely associated with the occurrence of lung injury, which has multiple etiologies and may result in fulminant respiratory failure and death (8-10). A large number of studies have confirmed that LPS induces ALI/ARDS in animals (11). During ALI/ARDS, the injured cells trigger a cascade of events, including acute inflammatory response, recruitment of immune cells and release of cytokines and chemokines (12). A549 cells, although a lung cancer cell line, are characterized as type II epithelial cells and frequently used as a model system for analyzing type II epithelial cells; they have been used in research investigating the mechanism of lung injury $(13,14)$. Prior to LPS being able to enter cells, it requires to be first recognized by and bind with LPS binding protein; it is then accepted and binds to the LPS receptor (15) molecule CD14 (16). However, CD14 lacks intracellular domains and is unable to transport signals through the cell membrane. Rather, CD14 presents LPS to Toll-like receptor 4 (TLR4). The compound is then bound with TLR4, which leads to the activation of multiple intracellular signaling components, including NF- $\mathrm{B}$ (17-19). Following its activation, $N F-\kappa B$ is able to enter into the nucleus to activate the transcription and translation of proinflammatory factors, such as IL-6, IL-8 and tumor necrosis factor (TNF)- $\alpha$ (20). Overwhelming pro-inflammatory responses are hallmarks of inflammation, which may lead to multiple organ failure and death. SARS-CoV-2 destroys the type II alveolar cells that secrete pulmonary surfactants and block TLR4 in the lungs, promoting ARDS and inflammation (21). Furthermore, the levels of soluble CD14 and TNF receptors 1 and 2 may be predictive of the risk of death in severe COVID-19 (22). Approximately $50 \%$ of patients with COVID-19 with critical disease die from the infection (23). COVID-19 morbidity and 
mortality are also associated with hyperinflammation $(24,25)$. Therefore, the modulation of CD14/TLR4-mediated LPS signaling may be an attractive target for defending against inflammation, including SARS-Cov-2 infection.

Anesthetic agents, including propofol, are commonly used for general anesthesia, as well as sedation in intensive care units (ICUs). Apart from its sedative effect, 2,6-diisopropylphenol (propofol) has been indicated to exert protective effects in various disease models, particularly in sepsis/endotoxemia models (26-29). In clinical practice, patients with inflammation that end up in the operating room or ICU are administered different anesthetics, including propofol. Since the start of the COVID-19 pandemic, an increasing number of patients with preexisting lung injury and inflammation are undergoing surgery or artificial ventilation under sedation at the ICU (30). In clinical situations, the onset of lung injury usually occurs prior to the administration of anesthesia or sedation to facilitate artificial ventilation. Whether post-treatment with propofol has an anti-inflammatory effect on these patients requires further exploration.

Despite the increase in the understanding of its pathophysiological processes, there are no specific pharmacological treatments for inflammation. The aim of the present study was to identify potential molecules that may effectively attenuate or inhibit the inflammatory and immune responses in ALI and ARDS, and evaluate the effect of post-treatment with propofol on the inflammatory and immune responses.

\section{Materials and methods}

Cell culture. A549 cells (donated by the cell bank in the Central Lab of China Medical University) were cultured in RPMI-1640 media (Invitrogen; Thermo Fisher Scientific, Inc.) supplemented with $10 \%$ FBS (Invitrogen; Thermo Fisher Scientific, Inc.). Cells were grown at $37^{\circ} \mathrm{C}$ in a humidified incubator with $5 \% \mathrm{CO}_{2}$ and then seeded at a density of $1 \times 10^{6}$ cells $/ \mathrm{ml}$. Cells were then treated with LPS (final concentration, $1 \mu \mathrm{g} / \mathrm{ml}$ for $2 \mathrm{~h}$; cat. no. 055:B5; L-2880; MilliporeSigma) and propofol at clinically relavant concentrations $(10,25$ and $50 \mu \mathrm{M}$, dissolved using 5\% glucose; $3 \mathrm{~h}$; Corden Pharma Caponago S.P.A.) following cell attachment to the bottom of the wells for $24 \mathrm{~h}$. Cell viability was determined using a trypan blue dye exclusion assay.

Protein extraction and immunoblotting. Protein was extracted from the treated cells using a commercially available kit (cat. no. SA4378; Nanjing Sunbio Technology Co., Ltd). The total protein concentration was determined using a BCA protein assay kit (cat. no. PA001-1; Signalway Antibody LCC). Total proteins (20 $\mu \mathrm{g}$ per lane) were separated using $10 \%$ SDS-PAGE, transferred onto a PVDF membrane (cat. no. abs931; Absin Bioscience Inc.) and blocked for $1 \mathrm{~h}$ at room temperature with $5 \%$ Difco $^{\mathrm{TM}}$ Skim Milk (BD Bioscience). For primary antibody incubation, membranes were exposed to anti-CD14 (dilution, 1:400; cat. no. sc-9150; Santa Cruz Biotechnology, Inc.), anti-TLR4 (dilution, 1:400; cat. no. sc-10741; Santa Cruz Biotechnology, Inc.) and anti- $\beta$-actin (dilution, 1:400; cat. no. sc-47778; Santa Cruz Biotechnology, Inc.) antibodies overnight at $4^{\circ} \mathrm{C}$. Membranes were washed in tris-buffered saline with Tween-20 and then incubated with a horseradish peroxidase-conjugated goat anti-rabbit IgG (dilution, 1:4,000; cat. no. ZB-2301; OriGene Technologies, Inc.) and goat anti-mouse IgG (dilution, 1:4,000; cat. no. ZB-2305; OriGene Technologies, Inc.) for $1 \mathrm{~h}$ at room temperature. Immunoreactive bands were visualized with enhanced chemiluminescence (Pierce; Thermo Fisher Scientific, Inc.). Densitometry was performed using ImageJ $1.37 \mathrm{c}$ software (National Institutes of Health). Western blot analysis was performed in triplicate for each experimental condition.

Reverse transcription-quantitative PCR (RT-qPCR). Total RNA was extracted using TRIzol ${ }^{\circledR}$ reagent (Thermo Fisher Scientific, Inc.). Next, total RNA (500 ng) was reverse-transcribed using $2 \mu \mathrm{l}$ Reverse Transcription 10X Buffer, $2 \mu \mathrm{l}$ dNTP mixture, $4 \mu \mathrm{l} \mathrm{MgCl}_{2}, 0.5 \mu \mathrm{l}$ recombinant RNasin ribonuclease inhibitor, $0.6522 \mu \mathrm{l}$ AMV reverse transcriptase and $1 \mu \mathrm{l}$ Oligo primer, which were components of a Reverse Transcription system kit (cat. no. A3500; Promega Corporation), according to the manufacturer's protocol, incubating at $42^{\circ} \mathrm{C}$ for $15 \mathrm{~min}$, $95^{\circ} \mathrm{C}$ for $5 \mathrm{~min}$ and $5^{\circ} \mathrm{C}$ for $5 \mathrm{~min}$. An ABI PRISM 7500 Real-Time PCR System (Applied Biosystems; Thermo Fisher Scientific, Inc.) was used for gene amplification and Hot-Start Activation was performed for cDNA at $95^{\circ} \mathrm{C}$ for $2 \mathrm{~min}$, followed by 40 cycles of $95^{\circ} \mathrm{C}$ for $3 \mathrm{sec}$, annealing/extension at $60^{\circ} \mathrm{C}$ for $30 \mathrm{sec}$ and dissociation at $60^{\circ} \mathrm{C}$. The total reaction volume $(25 \mu \mathrm{l})$ contained $12.5 \mu \mathrm{l}$ GoTaq qPCR Master Mix, $2 \mu \mathrm{l}$ primer, $2 \mu \mathrm{l} \mathrm{cDNA}$ and $8.5 \mu \mathrm{l}$ nuclear-free water, which were contained in GoTaq qPCR Master Mix Kit (cat. no. A6001; Promega Corporation). GAPDH was used as the reference gene and the relative of gene expression level was calculated as $\Delta \mathrm{Cq}=\mathrm{Cq}$ (gene)- $\mathrm{Cq}$ (reference). The fold change of gene expression was calculated using the $2^{-\Delta \Delta \mathrm{Cq}}$ method (31). The experiment was performed in triplicate. The primer sequences used were as follows: CD14 forward, 5'-GAGTCAACAGGG CATTCACC-3' and reverse, 5'-GGGACCGTAACAGGA AGGAT-3'; TLR4 forward, 5'-TAAGGTTGCCGCTTTCAC TT-3' and reverse, 5'-TGACCGAGCAGTTTCTGAGG-3'; and GAPDH forward, 5'-AAACCCATCACCATCTTCCAG-3' and reverse, 5'-AGGGGCCATCCACAGTCTTCT-3'.

Immunofluorescence staining. A549 cells were cultured on Lab-Tek chamber slides (cat. no. 155380; Nunc ${ }^{\text {TM }}$; Thermo Fisher Scientific, Inc.) for $24 \mathrm{~h}$. They were then stimulated with LPS $(1 \mu \mathrm{g} / \mathrm{ml})$ for $2 \mathrm{~h}$ and then treated with propofol $(1 \mu \mathrm{g} / \mathrm{ml})$ for $3 \mathrm{~h}$. Cells were fixed in $4 \%$ formaldehyde for $30 \mathrm{~min}$ at room temperature. For immunostaining, cells were permeabilized in $0.2 \%$ Triton X-100 for $5 \mathrm{~min}$ at room temperature and blocked with 5\% BSA (cat. no. A1933; MilliporeSigma) for $30 \mathrm{~min}$ at room temperature. Cells were incubated with rabbit polyclonal CD14 antibody (dilution, 1:160; cat. no. sc-9150; Santa Cruz Biotechnology, Inc.) and goat polyclonal TLR4 antibody (dilution, 1:160; cat. no. sc-16240; Santa Cruz Biotechnology, Inc.) overnight at $4^{\circ} \mathrm{C}$. Fluorescein-conjugated anti-goat IgG (dilution, 1:50; cat. no. SA00003-2; ProteinTech Group) and rhodamine-conjugated anti-rabbit IgG (dilution, 1:50; cat. no. SA00007-1; ProteinTech Group) antibodies were used as secondary antibodies with incubation at $37^{\circ} \mathrm{C}$ for $45 \mathrm{~min}$. Nuclei were counterstained with DAPI (cat. no. ab228549; Abcam) and cells were visualized using confocal microscopy (magnification, x400; FV1000; Olympus Corporation). 
ELISA. Cell culture supernatants were collected and stored at $-80^{\circ} \mathrm{C}$ in advance. The TNF- $\alpha$ levels were determined using a human TNF- $\alpha$ ELISA kit (cat. no. VAL 105; R\&D Systems) according to the manufacturer's protocol. This experiment was performed three times.

Statistical analysis. Values are expressed as the mean \pm standard deviation ( $\mathrm{n}=3$ ). SPSS version 17 (SPSS, Inc.) was used for all analyses. One-way ANOVA followed by Tukey's post-hoc test was used for comparisons between groups. $\mathrm{P}<0.05$ was considered to indicate a statistically significant difference.

\section{Results}

Post-treatment with propofol regulates CD14 expression in a dose-dependent manner. The expression of $\mathrm{CD} 14$ was detected by western blot analysis and RT-qPCR. As presented in Fig. 1, the CD14 level was significantly increased by treatment with LPS at both the protein and mRNA level in A549 cells. CD14 expression decreased significantly following post-treatment with propofol in a dose-dependent manner at both the protein and mRNA levels. Furthermore, CD14 protein was visualized $3 \mathrm{~h}$ after post-treatment with propofol using immunofluorescence microscopy and suppressed CD14 expression was observed (Fig. 2).

Post-treatment with propofol regulates TLR4 expression in a dose-dependent manner. TLR4 expression was analyzed in A549 cells using western blot analysis and RT-qPCR. The western blot results indicated that TLR4 expression increased significantly following treatment with LPS in A549 cells (Fig. 1C). Post-treatment with propofol decreased TLR4 expression in the A549 cells in a concentration-dependent manner. The RT-qPCR results exhibited a similar trend (Fig. 3), namely that LPS upregulated the mRNA levels of TLR4 and post-treatment with propofol reversed these increases in the mRNA levels of TLR4 in a concentration-dependent manner in A549 cells. The TLR4 protein levels were also determined using immunofluorescence microscopy following propofol treatment for $3 \mathrm{~h}$ and similar results were observed; TLR4 expression was increased following LPS treatment and suppressed following post-treatment with propofol (Fig. 2).

Post-treatment with propofol regulates TNF- $\alpha$ expression in a dose-dependent manner. TNF- $\alpha$ expression in A549 cells treated with LPS and propofol was determined using ELISA. As presented in Fig. 3, LPS significantly promoted the expression of TNF- $\alpha$ in the A549 cells. Post-treatment with propofol suppressed the expression of TNF- $\alpha$ in a dose-dependent manner in A549 cells.

\section{Discussion}

The present study investigated whether post-treatment with propofol has a positive role in protecting A549 cells against LPS-induced inflammation, and how propofol exerted its protective function. It was indicated that post-treatment with propofol markedly restored immune function in LPS-induced A549 cells, attenuating the stimulation of proinflammatory
A
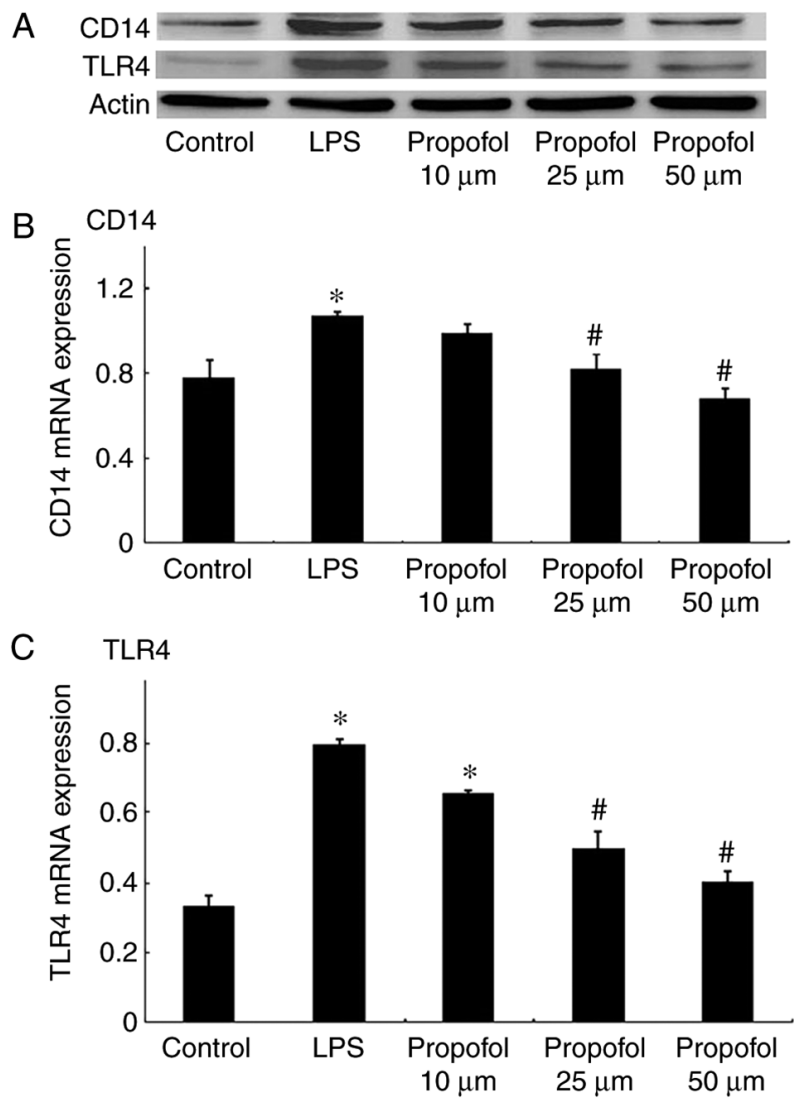

Figure 1. Post-treatment with propofol inhibits LPS-induced expression of CD14 and TLR4. (A) Western blot analysis indicated that LPS upregulated CD14 and TLR4 expression and post-treatment with propofol downregulated CD14 and TLR4 expression in A549 cells. (B) RT-qPCR suggested that the mRNA expression levels of CD14 increased in the A549 cell line when treated with LPS. The mRNA expression levels of CD14 decreased significantly in A549 cells treated with 25 or $50 \mu \mathrm{M}$ propofol vs. those in the control LPS group. (C) RT-qPCR indicated that the TLR4 mRNA expression levels increased in LPS-treated A549 cells. TLR4 expression decreased significantly in the A549 cells treated with 25 and $50 \mu \mathrm{M}$ propofol vs. that in the control LPS group. Data are derived from three independent experiments. * $\mathrm{P}<0.05$ vs. control group; ${ }^{\#} \mathrm{P}<0.05$ vs. LPS group. LPS, lipopolysaccharide; TLR4, Toll-like receptor 4; RT-qPCR, reverse transcription-quantitative PCR.

cytokines. It was also observed that the mechanism of action of post-treatment with propofol may involve the modulation of CD14 and TLR4 expression during protection against lung injury. The results of the present study indicated the protective role of post-treatment with propofol in LPS-induced inflammation and revealed that post-treatment with propofol mitigated inflammation by modulating CD14 and TLR 4 expression.

With the COVID-19 pandemic, inflammation and its alleviation have drawn ever increasing attention. Alveolar epithelial cells are frequently the first type of cell to suffer the damage caused by pathogenic microbial cells, which include not only the inflammatory and target cells but also active inflammatory and effector cells $(32,33)$. The A549 cell line, orignally a lung cancer cell line, is a widely used cell line in research on alveolar epithelial cell biology and its shared characteristics with type II alveolar epithelial cells have been demonstrated in vitro; the response of this cell line to various interventions is constant and repeatable, so it may be used in the study of relevant interventions $(34,35)$. 

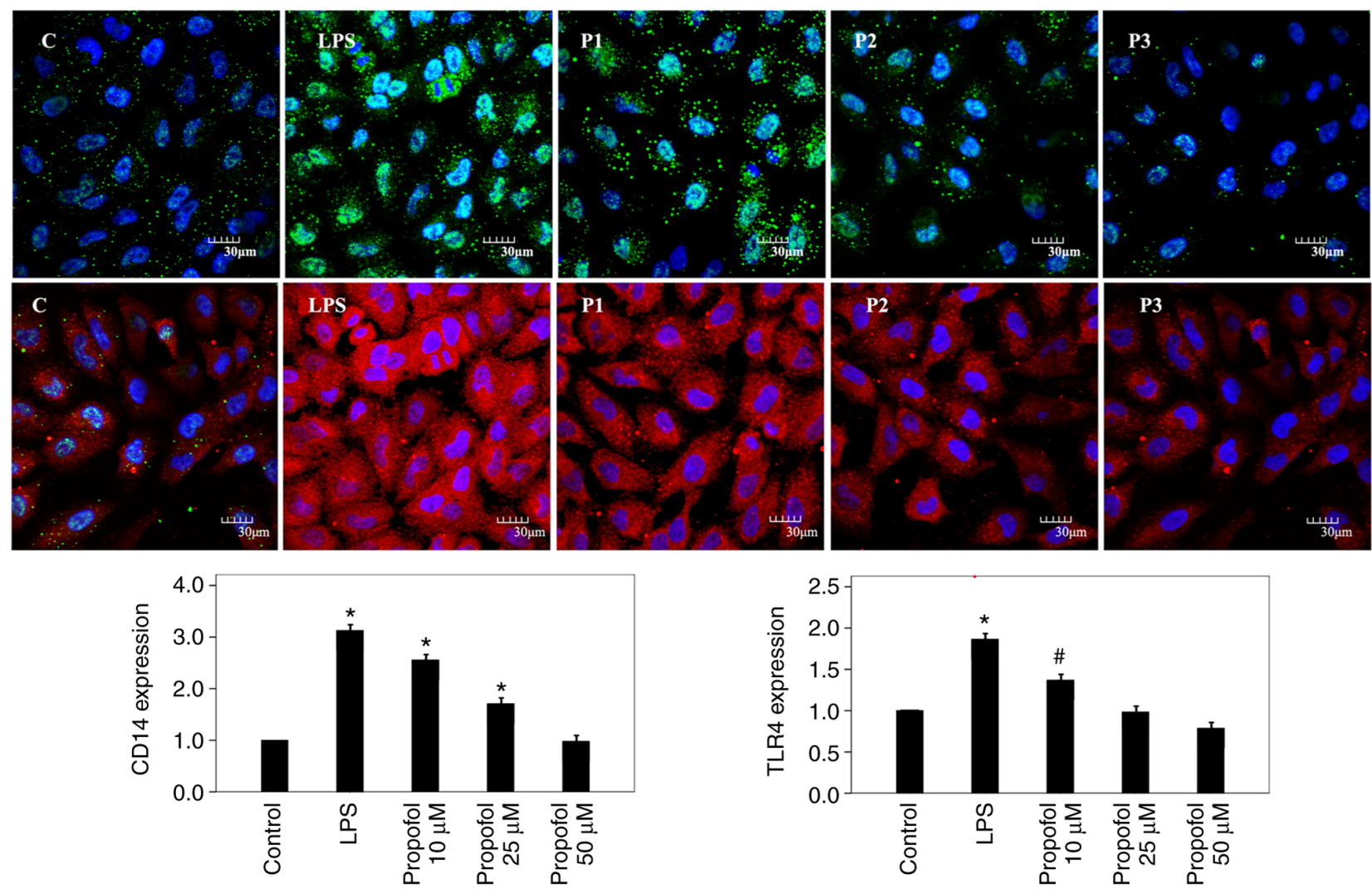

Figure 2. Post-treatment with propofol suppresses LPS-induced CD14 and TLR4 expression. Fluorescent microscope images displaying CD14 (green) and TLR4 (red) expression. Nuclei were stained with DAPI (blue). An increase in CD14 and TLR4 expression was observed in the LPS group. Post-treatment with propofol (10, 25 and $50 \mu \mathrm{M}$ ) suppressed CD14 and TLR4 expression (scale bars, $30 \mu \mathrm{M}$ ). Data are derived from three independent experiments. "P<0.05 vs. control group; ${ }^{\sharp} \mathrm{P}<0.05$ vs. LPS group. TLR4, Toll-like receptor 4; LPS, lipopolysaccharide.

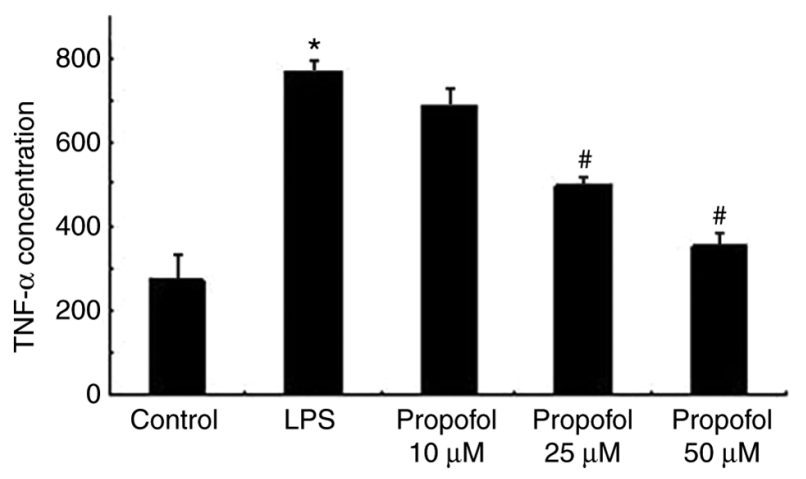

Figure 3. Post-treatment with propofol inhibits the LPS-induced expression of TNF- $\alpha$. ELISA indicated that the concentration of TNF- $\alpha$ was significantly increased in LPS-treated A549 cells. The concentration of TNF- $\alpha$ was significantly decreased in the A549 cells treated with 25 and $50 \mu \mathrm{M}$ propofol vs. the control LPS group. Data are derived from six independent experiments. ${ }^{*} \mathrm{P}<0.05$ vs. control group; ${ }^{\#} \mathrm{P}<0.05$ vs. LPS group. LPS, lipopolysaccharide; TNF- $\alpha$, tumor necrosis factor $\alpha$.

TLR- 4 is one of the most important receptors that recognize and initiate the inflammatory signal of LPS, as well as that of viruses, such as SARS-CoV-2 (36,37). TLR4-CD14 complexes may initiate the inflammatory signaling pathway of LPS and activate downstream cellular signaling pathways (38). TNF- $\alpha$ is an early endogenous mediator and an important signaling factor, produced mainly by the alveolar macrophages, which is released early in the inflammatory response. TNF- $\alpha$ is able to initiate, amplify and continue the systemic or local inflammatory reaction, as well as accelerate pulmonary toxicity (39).

Propofol is considered to be one of the most commonly used drugs for anesthesia and sedation in clinical practice. Certain studies have proven its immunoregulatory and anti-inflammatory effects. Propofol alleviated lung injury in neonatal rats with LPS-induced ALI by preventing inflammation and oxidative stress through the regulation of $\mathrm{p} 38$ MAPK/NF- $\kappa B$ signaling pathway activity and NLR family pyrin domain containing 3 (NLRP3) inflammasome expression (40). Furthermore, Zhao et al (41) reported that propofol reduced endotoxin-induced cardiomyocyte injury by inhibiting inflammation and apoptosis through the peroxisome proliferator-activated receptor $\gamma /$ high mobility group box protein 1/NLRP3 axis. However, the effects and mechanisms remain to be fully elucidated, particularly when patients with pre-existing inflammation or ALI/ARDS are placed under propofol-induced sedation or anesthesia. In the present study, TLR4 was indicated to have a marked impact on the molecular signaling pathways of inflammation, particularly in the identification of pathogens associated with inflammatory molecular patterns by combining with CD14. Certain previous reports have indicated that propofol was able to inhibit the expression of TLR4 and the activation of downstream molecules $(42,43)$, which is in line with the results of the present study. Post-treatment with propofol reduced the LPS-induced expression of TLR4 and CD14 at both the protein and mRNA levels in a concentration-dependent 
manner in A549 cells. Therefore, it may be hypothesized that post-treatment with propofol is able to inhibit the inflammatory reaction by reducing TLR4 and CD14 levels during ALI/ARDS. To further investigate the anti-inflammatory effect of post-treatment with propofol, the expression of TNF- $\alpha$ in A549 cells treated with LPS and propofol was analyzed. The present results indicated that post-treatment with propofol can alleviate the LPS-induced inflammation of A549 cells.

In a previous study, patients required an average blood propofol concentration of $4.05 \pm 1.01 \mu \mathrm{g} / \mathrm{ml}$ for major surgery and $2.97 \pm 1.07 \mu \mathrm{g} / \mathrm{ml}$ for non-major surgery $(12-29 \mu \mathrm{M})(42,44)$. Blood concentrations of propofol may reach $56 \mu \mathrm{M}$ after a bolus injection $(43,45)$, with a peak of $67 \mu \mathrm{M}(44,46)$. Therefore, $10-50 \mu \mathrm{M}$ was considered as the range of clinically achievable concentrations during propofol anesthesia. However, $10 \mu \mathrm{M}$ propofol had no statistically significant anti-inflammatory effect in LPS-induced A549 cells, suggesting it was too low to exert an anti-inflammatory effect.

To the best of our knowledge, no studies have investigated post-treatment with propofol for the suppression of inflammation. The present study indicated that propofol suppressed LPS-induced CD14, TLR4 and TNF- $\alpha$ expression in a concentration-dependent manner in A549 cells, providing guidance on choosing anesthetics. Propofol may be a better choice for patients with pre-existing lung injury due to its anti-inflammatory effects. For patients with pre-existing ALI and ARDS, propofol may be a suitable choice for anesthesia or sedation.

The present study was not without its limitations. First, it was an in vitro study; further in vivo animal studies should be performed to verify the mechanism. Furthermore, since propofol is widely used in the clinic, clinical trials with actual patients will provide more reliable results on its effect on inflammation and guidance for medical practice.

In conclusion, it was confirmed that post-treatment with a clinically relevant concentration of propofol had important anti-inflammatory effects on LPS-induced alveolar epithelial cells. This beneficial effect of post-treatment with propofol on cell viability was mediated by inhibition of CD14 and TLR4 expression. The present study provided a pharmacological basis for the clinical application of the anesthetic compound propofol in patients with inflammation.

\section{Acknowledgements}

The authors deeply appreciate the kind help from Ms. Min Shi (National Institute of Environmental Health Science, National Institutes of Health) with the language editing of the manuscript.

\section{Funding}

This work was supported by the National Natural Science Foundation of China (grant no. 81302534).

\section{Availability of data and materials}

The datasets used and/or analyzed during the current study are available from the corresponding author on reasonable request.

\section{Authors' contributions}

XY performed the experiments and the data analysis. LM contributed to the design of the experiments and writing the manuscript. XY and LM confirm the authenticity of all the raw data. All authors have read and approved the final manuscript.

\section{Ethics approval and consent to participate}

Not applicable.

\section{Patient consent for publication}

Not applicable.

\section{Competing interests}

The authors declare that they have no competing interests.

\section{References}

1. Chen N, Zhou M, Dong X, Qu J, Gong F, Han Y, Qiu Y, Wang J, Liu Y, Wei Y, et al: Epidemiological and clinical characteristics of 99 cases of 2019 novel coronavirus pneumonia in Wuhan, China: A descriptive study. Lancet 395: 507-513, 2020.

2. Dorward DA, Russell CD, Um IH, Elshani M, Armstrong SD, Penrice-Randal R, Millar T, Lerpiniere CEB, Tagliavini G, Hartley CS, et al: Tissue-specific immunopathology in fatal COVID-19. Am J Respir Crit Care Med 203: 192-201, 2021.

3. Pairo-Castineira E, Clohisey S, Klaric L, Bretherick AD, Rawlik K, Pasko D, Walker S, Parkinson N, Fourman MH, Russell CD, et al: Genetic mechanisms of critical illness in COVID-19. Nature 591: 92-98, 2021.

4. Baedorf Kassis E, Schaefer MS, Maley JH, Hoenig B, Loo Y, Hayes MM, Moskowitz A and Talmor D: Transpulmonary pressure measurements and lung mechanics in patients with early ARDS and SARS-CoV-2. J Crit Care 63: 106-112, 2021.

5. Smith S, Skerrett SJ, Chi EY, Jonas M, Mohler K and Wilson CB: The locus of tumor necrosis factor-alpha action in lung inflammation. Am J Respir Cell Mol Biol 19: 881-891, 1998.

6. Knox KW, Vesk M and Work E: Relation between excreted lipopolysaccharide complexes and surface structures of a lysine-limited culture of Escherichia coli. J Bacteriol 92: 1206-1217, 1996.

7. Nova Z, Skovierova $\mathrm{H}$ and Calkovska A: Alveolar-capillary membrane-related pulmonary cells as a target in endotoxin-induced acute lung injury. Int J Mol Sci 20: 831, 2019.

8. Chacko B, Peter JV, Tharyan P, John G and Jeyaseelan L: Pressure-controlled versus volume-controlled ventilation for acute respiratory failure due to acute lung injury (ALI) or acute respiratory distress syndrome (ARDS). Cochrane Database Syst Rev 1: CD008807, 2015.

9. Zhu T, Zhang W, Feng SJ and Yu HP: Emodin suppresses LPS-induced inflammation in RAW264.7 cells through a PPAR $\gamma$-dependent pathway. Int Immunopharmacol 34: 16-24, 2016.

10. Sivanantham A, Pattarayan D, Bethunaickan R, Kar A, Mahapatra SK, Thimmulappa RK, Palanichamy R and Rajasekaran S: Tannic acid protects against experimental acute lung injury through downregulation of TLR4 and MAPK. J Cell Physiol 234: 6463-6476, 2019.

11. Li HF, Wu YL, Tseng TL, Chao SW, Lin $\mathrm{H}$ and Chen HH: Inhibition of miR-155 potentially protects against lipopolysaccharide-induced acute lung injury through the IRF2BP2-NFAT1 pathway. Am J Physiol Cell Physiol 319: C1070-C1081, 2020.

12. Wang H, Wang T, Yuan Z, Cao Y, Zhou Y, He J, Shen Y, Zeng N, Dai L, Wen F and Chen L: Role of receptor for advanced glycation end products in regulating lung fluid balance in lipopolysaccharide-induced acute lung injury and infection-related acute respiratory distress syndrome. Shock 50: 472-482, 2018.

13. Meyer K, Patra T, Vijayamahantesh and Ray R: SARS-CoV-2 spike protein induces paracrine senescence and leukocyte adhesionin endothelial cells. J Virol 95: E0079421, 2021. 
14. SchillerHB, van BreugelMandNawijn MC:SARS-CoV-2-specific hotspots in virus-host interaction networks. Nat Immunol 22: 806-808, 2021

15. Nakamura M, Takeuchi T, Shirakawa $K$ and Furusako S: Anti-human CD14 monoclonal antibody improves survival following sepsis induced by endotoxin, but not following polymicrobial infection. Eur J Pharmacol 806: 18-24, 2017.

16. Lappin MJ, Brown V, Zaric SS, Lundy FT, Coulter WA and Irwin CR: Interferon- $\gamma$ stimulates CD14, TLR2 and TLR4 mRNA expression in gingival fibroblasts increasing responsiveness to bacterial challenge. Arch Oral Biol 61: 36-43, 2016

17. Huynh DTN, Baek N, Sim S, Myung CS and Heo KS: Minor ginsenoside $\mathrm{Rg} 2$ and $\mathrm{Rh} 1$ attenuates LPS-induced acute liver and kidney damages via downregulating activation of TLR4-STAT1 and inflammatory cytokine production in macrophages. Int J Mol Sci 21: 6656, 2020

18. Iannucci A, Caneparo V, Raviola S, Debernardi I, Colangelo D, Miggiano R, Griffante G, Landolfo S, Gariglio M and De Andrea M: Toll-like receptor 4-mediated inflammation triggered by extracellular IFI16 is enhanced by lipopolysaccharide binding. PLoS Pathog 16: e1008811, 2020.

19. Plociennikowska A, Hromada-Judycka A, Dembinska J, Roszczenko P. Ciesielska A and Kwiatkowska K: Contribution of CD14 and TLR4 to changes of the PI(4,5)P2 level in LPS-stimulated cells. J Leukoc Biol 100: 1363-1373, 2016.

20. Liu P, Cui L and Shen L: Knockdown of TRIM52 alleviates LPS-induced inflammatory injury in human periodontal ligament cells through the TLR4/NF-kB pathway. Biosci Rep 40 : BSR20201223, 2020.

21. Aboudounya MM and Heads RJ: COVID-19 and toll-like receptor 4 (TLR4): SARS-CoV-2 may bind and activate TLR4 to Increase ACE2 expression, facilitating entry and causing hyperinflammation. Mediators Inflamm 2021: 8874339, 2021.

22. Bowman ER, Cameron CMA, Avery A, Gabriel J, Kettelhut A, Hecker M, Sontich CU, Tamilselvan B, Nichols CN, Richardson B, et al: Levels of soluble CD14 and tumor necrosis factor receptors 1 and 2 may be predictive of death in severe coronavirus disease 2019. J Infect Dis 223: 805-810, 2021.

23. Singhal S, Kumar P, Singh S, Saha S and Dey AB: Clinical features and outcomes of COVID-19 in older adults: A systematic review and meta-analysis. BMC Geriatr 21: 321, 2021.

24. Fernandez-Botran R, Furmanek S, Ambadapoodi RS, Exposito Gonzalez E, Cahill M, Carrico R, Akca O and Ramirez JA; University of Louisville COVID-19 Study Group: Association and predictive value of biomarkers with severe outcomes in hospitalized patients with SARS-CoV-2 infection. Cytokine 149: 155755, 2022.

25. Tufan A, Avanoglu Guler A and Matucci-Cerinic M: COVID-19, immune system response, hyperinflammation and repurposing antirheumatic drugs. Turk J Med Sci 50: 620-632, 2020.

26. Zheng X, Huang H, Liu J, Li M, Liu M and Luo T: Propofol attenuates inflammatory response in LPS-activated microglia by regulating the miR-155/SOCS1 pathway. Inflammation 41: 11-19, 2018.

27. Yang N, Liang Y, Yang $P$ and Ji F: Propofol suppresses LPS-induced nuclear accumulation of HIF-1 $\alpha$ and tumor aggressiveness in non-small cell lung cancer. Oncol Rep 37: 2611-2619, 2017.

28. Yeh CH, Cho W, So EC, Chu CC, Lin MC, Wang JJ and Hsing CH: Propofol inhibits lipopolysaccharide-induced lung epithelial cell injury by reducing hypoxia-inducible factor-1alpha expression. Br J Anaesth 106: 590-599, 2011.

29. Huang T, Zhang Y, Wang C and Gao J: Propofol reduces acute lung injury by up-regulating gamma-aminobutyric acid type a receptors. Exp Mol Pathol 110: 104295, 2019.
30. Witenko CJ, Littlefield AJ, Abedian S, An A, Barie PS and Berger K: The safety of continuous infusion propofol in mechanically ventilated adults with coronavirus disease 2019. Ann Pharmacother 56: 5-15, 2022.

31. Livak KJ and Schmittgen TD: Analysis of relative gene expression data using real-time quantitative PCR and the 2(-Delta Delta $\mathrm{C}(\mathrm{T})$ ) method. Methods 25: 402-408, 2001

32. Gerard L, Lecocq M, Bouzin C, Hoton D, Schmit G, Pereira JP, Montiel V, Plante-Bordeneuve T, Laterre PF and Pilette C: Increased angiotensin-converting enzyme 2 and loss of alveolar type II Cells in COVID-19 Related ARDS. Am J Respir Crit Care Med 204: 1024-1034, 2021.

33. Bridges JP, Vladar EK, Huang H and Mason RJ: Respiratory epithelial cell responses to SARS-CoV-2 in COVID-19. Thorax 77: 203-209, 2022.

34. Sasaki M, Kishimoto M, Itakura Y, Tabata K, Intaruck K, Uemura K, Toba S, Sanaki T, Sato A, Hall WW, et al: Air-liquid interphase culture confers SARS-CoV-2 susceptibility to A549 alveolar epithelial cells. Biochem Biophys Res Commun 577: 146-151, 2021.

35. Wang Y, Fan Y, Huang Y, Du T, Liu Z, Huang D, Wang Y, Wang $N$ and Zhang P: TRIM28 regulates SARS-CoV-2 cell entry by targeting ACE2. Cell Signal 85: 110064, 2021.

36. Choudhury A and Mukherjee S: In silico studies on the comparative characterization of the interactions of SARS-CoV-2 spike glycoprotein with ACE-2 receptor homologs and human TLRs. J Med Virol 92: 2105-2113, 2020.

37. Leifer CA and Medvedev AE: Molecular mechanisms of regulation of Toll-like receptor signaling. J Leukoc Biol 100: 927-941, 2016.

38. Kim S, Kim SY, Pribis JP, Lotze M, Mollen KP, Shapiro R, Loughran P, Scott MJ and Billiar TR: Signaling of high mobility group box 1 (HMGB1) through toll-like receptor 4 in macrophages requires CD14. Mol Med 19: 88-98, 2013.

39. Sancho Ferrando E, Hanslin K, Hultström M, Larsson A, Frithiof R and Lipcsey M; Uppsala Intensive Care COVID-19 Research Group: Soluble TNF receptors predict acute kidney injury and mortality in critically ill COVID-19 patients: A prospective observational study. Cytokine 149: 155727, 2022.

40. Yu X and Li C: Protective effects of propofol on experimental neonatal acute lung injury. Mol Med Rep 19: 4507-4513, 2019.

41. Zhao H, Gu Y and Chen H: Propofol ameliorates endotoxin induced myocardial cell injury by inhibiting inflammation and apoptosis via the PPAR $\gamma / \mathrm{HMGB} 1 / \mathrm{NLRP} 3$ axis. Mol Med Rep 23: 176, 2021

42. Ma L, Yang Y, Sun X, Jiang M, Ma Y, Yang X and Guo Z: Propofol regulates the expression of TLR4 through miR-21 in human umbilical vein endothelial cells. Mol Med Rep 16: 9074-9080, 2017

43. Wang Y, Lin C, Wang J, Zhou M, Fang T, Miao L and Wei Y: Propofol rescues LPS-induced toxicity in HRT-8/SVneo cells via miR-216a-5p/TLR4 axis. Arch Gynecol Obstet: Jan 4, 2022 (Epub ahead of print).

44. Shafer A, Doze VA, Shafer SL and White PF: Pharmacokinetics and pharmacodynamics of propofol infusions during general anesthesia. Anesthesiology 69: 348-356, 1988.

45. Gepts E, Camu F, Cockshott ID and Douglas EJ: Disposition of propofol administered as constant rate intravenous infusions in humans. Anesth Analg 66: 1256-1263, 1987.

46. Schüttler J and Ihmsen H: Population pharmacokinetics of propofol: A multicenter study. Anesthesiology 92: 727-738, 2000.

This work is licensed under a Creative Commons Attribution-NonCommercial-NoDerivatives 4.0 International (CC BY-NC-ND 4.0) License. 